\title{
Antecedents of Organizational Culture in its Relevance with Change Management, Moderating Role of Transformational Leadership and Employee Empowerment An Analysis of HEI of Peshawar Region
}

\author{
ZUNNOORAIN KHAN \\ Assistant Professor, City university of Science and \\ Information Technology Peshawar, Pakistan. \\ Email: zunnoorainkhann@ gmail.com \\ Dr. FUWAD BASHIR \\ Associate Professor, SZBAIST Islamabad. \\ SHAHZAD KHAN \\ Assistant Professor, University of Haripur, Pakistan. \\ Email: Shahzadkhan@uoh.edu.pk
}

\begin{abstract}
The rationale of the research is to investigate the importance of organizational culture in a Dynamic era of 21 st century where only those organizations remain triumphant who transform change in their business. Whenever organization focused on change they encounter intense resistant from their employees as well as for conceptualizing of organization, culture conceived either as a variable or as a root metaphor. Philosophical stance of research was based on positivism and follows more deductive approach for this study. Cross sectional data of ten private sector organizations of Peshawar region were chosen. The findings of the study were moderately interesting in terms of change management with the important role of leadership found insignificant $p>0.051$ and but shows weak relevance. However the results of organizational culture and change management were found significant $P<0.01$ at $1 \%$ level of significance. Recommendation portion of the study suggest us that for the success of an organization culture play pivotal role in the dynamic parameters of change. On the other hand the role of empowerment played significant role for producing better organizational culture.
\end{abstract}

Keywords: Organizational Culture, Organizational change, Leadership, Empowerment.

\section{Introduction}

Organizational Change management is reasonably new and emerging concept reflected on under Organizational Culture. It was in 1990s that this concept came up on the horizon of Organizational Culture and still in continuation at a steady rate towards the maturity. According to the definition of (Franken, Edwards, \& Lambert, 2009), Change Management (CM) is, the behavior that (a) crosses the limits of basic requirements of the job (fulfills the limits and goes beyond them), (b) is to a large degree discretionary, and (c) is beneficial to the organization. So basically OCM is to benefit the organization by showing productive and positive behavior from the perspective of employees.

Organizational culture with reference to change management has been recognized as an important influential aspect in analyzing organizations in numerous contexts. To remain competitive in such a turbulent environment where business has been increasingly complex and competitive, organizations has to 
be flexible as well as make themselves alert with the business climates. Organizations which remain static and do not improve in terms of competition will face gradual downturn in the performance of an organization it is also dependent on how well the organization and people understand the need for the change and the process involved. Organizations functioned for furtherance as well as for the collective growth of the societies. Organizations in $21^{\text {st }}$ century can only be successive if they invest on their employees which give them better and profound results in such a turbulent environment. Culture of an organization simply explains the norms and values which individuals contain in a particular organization. In such a dynamic and unstable environment where organizations face intense competition can only be survive if they continuously adopt change in their system. Previous studies on organizational culture discussed the importance of culture and its relationships with change management (Priola \& Hurrell, 2011) similar another study of (Hatch \& Zilber, 2012) every individual encounter with organizational culture and responses differently with the pivotal and peripheral norms of an organization through which they stand out in a particular system. The rationale of the research is to investigate the importance of organizational culture in a Dynamic era of $21^{\text {st }}$ century where only those organizations remain triumphant who transform change in their business.

Whenever organization focused on change they encounter intense resistant from their employees as well as for conceptualizing of organization, organizational culture considered either as a root metaphor or as a variable. Currently we are positioned in a very regularly intensifying global business environment, where change has become the integral entity for success and for prospers results. For instance; different industries and governmental organizations constantly focused on their operations and align them with the business environment (Burnes, 2004; Burnes \& Cooke, 2012). According to the study of (James, 2015) leaders and organizations are also changing with the change response and shift in strategic move, from effectively managing mass markets and tangible properties to innovation, knowledge management and human resources. With the study on change management there are different approaches and procedures have been suggested for managing change, but in actual change vary with the structure, systems, strategies and human resources of the organizations.

\section{Significance of Study}

Current study has particular implication on several counts. First, it validated the use of Denison (2014) 60 items on organizational culture facets for measuring the culture of organization. Second, econometrically determine whether the organizational culture facets determine the change management. Third, it determines the existence of leadership and empowerment in Pakistani situation, and whether the leadership and empowerment moderates between the organizational culture and change management. Our research will have significance for both practical and theoretical perspectives. Therefore, the study helps us to bridge the gap related to organizational culture and change management. This study benefit not only in research and education but also in business as well. The dynamic and competitive environment forces an organization to meet the multiple demands of the stakeholders i.e. customers, employees, and organization. This research contributed towards: Research, Theoretical knowledge and Policy \& Practice

\section{Aim of the Study}

The purpose of the study is to find out the facets of organizational culture with its significance related to change management. Moreover, the basic purpose of the study is to contribute to the development of a systematic and practical approach for establishing the missing links between organizational culture and change management in Pakistan developmental sector with leadership and empowerment

\section{Research Objectives}

$>$ To investigate the Denison model for organizational culture and its four major facets with its effect on change management 
To evaluate whether leadership and empowerment moderates relationship between organizational culture and change management

$>$ To provide policy and suggestions based on research findings

\section{Research Questions}

$>$ Does Denison model for organizational culture and its four major factors effect on change management or not?

$>$ Whether or not leadership and empowerment moderates the relationship between organizational culture and change management?

\section{Literature Review}

\section{Concepts and Definitions}

\section{Organizational Culture}

Based on the review connected with Schein (2010) Organizational culture is theorized for instance the layout connected with discussed essential assumptions figured out by the party because it resolved it's difficulties connected with external variation in addition to internal integration, that's worked well enough for being regarded good in addition to, for that reason, for being coached in order to brand new customers seeing that the correct way in order to perceive, imagine, in addition to think regarding those difficulties. Schein $(1984,2010)$ argues of which tradition manifests themselves in diverse levels in the firm. He differentiates about three stages of organizational culture, good scope from the cultural phenomenon's field of vision on the onlooker. The initial stage symbolizes your artifacts which have been your noticeable goods or bodily manifestations of organization's tradition. For instance, your structure, office format, technologies, outfit program code, types of tackle, noticeable behavior habits, seen rituals in addition to events, in addition to released paperwork. Though artifacts are generally all to easy to notice, they may be complicated in order to understand. One example is, we can easily summarize what exactly habits connected with efficiency data work with are generally discernible in the firm however, not why your organization's customers conduct themselves the way they complete while using data.

The second stage includes your espoused beliefs in addition to morals, or about norms, ideas, targets, in addition to goals, from the organizational party. Analyzing when it reaches this stage increases the understanding of the organization's tradition but may possibly indicate your members' rationalizations or goals. Espoused beliefs might be fuzy in addition to contrary, for instance as soon as a business promises to utilize efficiency administration both to lessen the price in order to boost the products it's efficiency. The third stage, the basic actual assumptions, provides a more deeply comprehension of the organization's tradition. Schein (2010) argued of which failure to understand your structure connected with essential assumptions will always make the item more challenging to create good sense from the more noticeable manifestations connected with culture-for case, the way to understand your artifacts appropriately or how much credence to provide your espoused beliefs. Standard assumptions are the spontaneous, taken-forgranted, in addition to non-negotiable morals in addition to beliefs of which effect exactly how party customers imagine, look at, in addition to feel about items in addition to guide their own behavior. Schein (1984) points out of which essential assumptions are generally figured out replies of which started seeing that espoused beliefs. Every time a worth is employed to steer the behavior, understanding that behavior will be repeatedly seen to unravel an issue, on-line will probably more and more turn into the actual supposition about how precisely items are really. Seeing that this kind of supposition will be significantly taken for granted, the item sheds beyond brain. Schein (1996) known essential assumptions because "essence connected with tradition." They are your hardest to switch and may even possibly be considered as the "source connected with resistance" (Schein, 1992) or even a "source connected with preventive routines" (Argyris, 1991) in opposition to understanding in addition to transform throughout companies. 


\section{Theoretical Reflection}

\section{Daniel R Denison Model}

Denison model described four organizational cultural dimensions that are described below:

\section{Involvement}

According to the study of Denison (2004) in which author describe about the significance of organizational culture with its four traits in which involvement was one of them those organizations want to achieve astonishing in success they empower their people, focused on group cohesiveness and make teams in such a manner to achieve organizational goals in a more directive way, enrich human capability plus build up human competency at all levels. Individual employee feel that their work has been recognized and some input into decisions make different which ultimately make them to own organization for achievement.

Furthermore Denison (2006) author summarize the relevance associated with organizational way of life which consists of a number of features where involvement had been one of them people companies need to attain shocking within achievements these people inspire their own people, devoted to team cohesiveness along with help make clubs in their normal approach to attain organizational ambitions in a very more directive technique, greatly improve man potential in addition build man skill in any way degrees. Individual worker believe their own perform may be identified and several insight straight into choices help make various which in turn in the end make sure they are owning corporation for accomplishment.

\section{Identifying gaps}

According to the study of Lok \& Crawford (1999) examine the relationship between change management and organizational culture with its impact on organizational development in this study author uses the primary data comprises of questionnaires for nurses of different hospital of Australia and analyze results on SPSS results were quite significant and reliability of the items were quite acceptable.

Findings of the study shows strong relationship between leadership and commitment however when compare with other variables small association lies between age of the respondent and commitment according to the study researchers reveal weak association between culture of an organization with commitment. Furthermore, Lok\& Crawford (2004) works on the same title with cross national comparison. This study examined the role of organizational culture with change management and leadership styles samples were collected from Hong Kong and Australian managers. It's a quantitative study based on adopted questionnaires. Results of the study show significant relationship between leadership and change management.

Kavanagh (2006) investigates the role of leadership and change management with the acceptance of culture values that lies in a particular system it's a longitudinal study and examined three large multi-site organizations for this study researcher did quantitative and qualitative approach for analysis. Findings of the study concluded that change can imposed from leaders with its strong approach towards turbulent environment, and it is often the pace of change that inhibits the successful re-engineering of the culture. According to this study the stance of leaders play significant role for transforming organizations to ensure individuals change is better for organization and accept changes prompted by merger.

Another study conducted in Pakistan by Ahmad (2012) on the importance of organizational culture with its role on the commitment of an employees' it's an exploratory research to reconnoiter the impact of organizational culture. Quantitative data were selected for this study and distributed questionnaires to 60 employees in Comsats Institute of Information Technology. Results of the study show that involvement of 
an employee is highly correlated with organizational culture. Likewise, other magnitudes of organizational culture have significantly positive relationship with the transformational leadership.

This research study selected samples from few cities of Pakistan; Forthcoming studies could select further more cities of Pakistan for sampling. Author of the paper selected simple random sampling, according to this paper future work could use some other sampling technique like stratified random sampling with more sample size. According to the study of (Cameron \& Green, 2004) the importance of change management with its role of organizational culture and readiness for change is more important for any organization in $21^{\text {st }}$ century.

Primary purpose of this study was to model the interface between the organizational culture and change describing the ways in which leader's understand the dynamics of organizational culture that affects the implementation in change process. For this study author choose qualitative approach for data collection and for data collection top 25 ranked universities from the Association of American Universities. Observations, interviews, and reflexive hypothesis testing served as the primary means of data collection, results portion of the study reveal that organizational culture play significant role on both the process and outcomes of change.

Numerous other studies highlight the same issue in their studies and explained change management is of the central proficiency for business leaders in $21^{\text {st }}$ century because without change organizations remain static and there is no future of static organizations.

Most of the studies were chosen empirical research approach for analysis purposes and selected both service and goods sectors for data collections almost collective responded of these studies were more than 5000 employees' from different organizations and they come to the point whenever we are discussion about the change management leadership has standing and organizations has to relies significant stance of their roles for the success and development of an organization. Charismatic is one of the facets of transformational leadership that can mobilize individuals' in an organization and aware them for the readiness of the change, role of leadership play pivotal role in building a trust among employees' and make them committed towards the organizational goals.

\section{Conceptual Frame work}

\section{Independent Variable}

The four major factors of organizational culture identified by (Denison, Nieminen, \& Kotrba, 2014)are independent variables i.e. Adaptability, Mission, Consistency, Involvement

\section{Dependent Variable}

Change management was our dependent variable. The construct of change management is based on operational definition provided by Kotter (2011)

\section{Moderating Variable}

Leadership and empowerment is playing moderating role in the relationship of organizational culture and change management. Leadership will be studied through two dimensions namely; transformational and transcriptional 
Denison model 2011

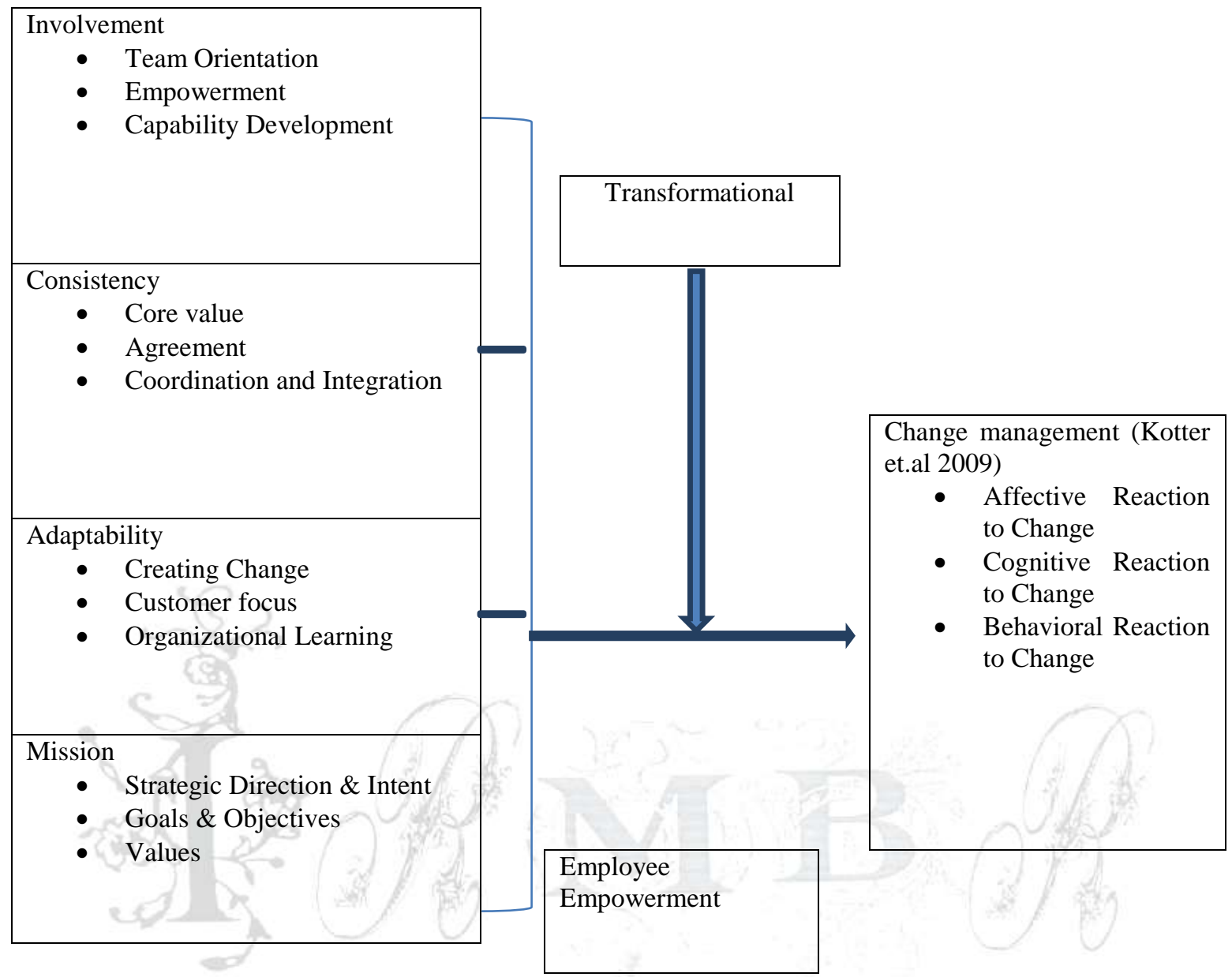

\section{Proposed Research Methodology}

\section{Sample Selecting}

For current study convenient sampling were used for data collection. Four universities were selected from the public sector in which the Institute of management sciences, University of Peshawar Department of Management studies; Shaheed Benazir Bhutto Women University and Islamia College University were included. Four universities were selected from private sector in which City university of science \& information technology, Preston University Peshawar campus, Cecos University of Engineering and Emerging Sciences and Qurtaba University were included. Questionnaires distributed and to be filled by the faculty of management sciences providing their services in eight HEC recognized universities of Peshawar region,

\section{Population Frame}

For current study Peshawar region were selected in which there are 05 public and 06 private sector all the public and private universities are the population of the study. 


\section{Instrument (Questionnaire)}

Two different tested questionnaires were used in this study for Organizational Culture (OC) and Change Management (CM) separately. The questionnaire for this study was divided into three sections. Section 1 was related to the Organizational culture and its measures, Section 2 was related to the Change Management and its measures and Section 3 was related to Demographic characteristics. The questionnaire that has been used for this study is mentioned at the end in the appendix.

The questionnaire that was developed and used for this research was not self-administered. In fact it was handed over to the faculty members of the respective Universities and then that respective universities filled it from his employees. The reliability of the questionnaires selected from literature was high.

\section{Results}

\section{Demographic Analysis Results}

The demographic analysis is conducted to check for the variance in terms of gender, designation, of the respondents. Like for gender to check the ratio of male and female respondents, for designation to see the ratio of designation difference. Following table provide frequency distribution of 200 respondents which explain that $28 \%$ respondents were Professors, $77 \%$ were related with the job designation of Associate Professor, as well as $71 \%$ respondents were assistant professor and about $24 \%$ respondents were lecturers

Table.1: Frequencies of respondents

\begin{tabular}{|c|c|c|c|}
\hline$\left(-2 x^{2}\right.$ & Frequency & Percent & $x$ \\
\hline $\begin{array}{l}\text { Gender } \\
\text { Male } \\
\text { Female }\end{array}$ & $\begin{array}{l}133 \\
67\end{array}$ & $\begin{array}{l}66.5 \\
33.5\end{array}$ & \\
\hline $\begin{array}{l}\text { Designation } \\
\text { Professor } \\
\text { Associate Professor } \\
\text { Assistant Professor } \\
\text { Lecturer }\end{array}$ & $\begin{array}{l}28 \\
77 \\
71 \\
24\end{array}$ & $\begin{array}{l}14.0 \\
38.5 \\
35.5 \\
12.0\end{array}$ & \\
\hline
\end{tabular}

Table.2: Reliability of items

\begin{tabular}{|llccc|}
\hline Variables & Sub-variables & $\begin{array}{c}\text { No of } \\
\text { items }\end{array}$ & $\begin{array}{c}\text { Reliability } \\
\text { coefficient }\end{array}$ & Source \\
\hline Denison & Involvement & 15 & 0.924 & $\begin{array}{c}\text { Denison } \\
\text { Cultural }\end{array}$ \\
Dimensions & Consistency & 15 & 0.848 & (2014) \\
& Adaptability & 15 & 0.903 & \\
Mission & 15 & 0.775 & \\
Change & Affective Reaction & 6 & 0.995 & $\begin{array}{c}\text { Kotter et al. } \\
\text { Management }\end{array}$ \\
$\begin{array}{llll}\text { Cognitive Reaction } \\
\text { Behavioral Reaction }\end{array}$ & 6 & 0.986 & \\
Transformational & Idealized Influence & 8 & 0.993 & Bass \\
Leadership & Inspirational motivation & & & \&Avolio, \\
& Intellectual stimulation & & & (1995) \\
\hline
\end{tabular}




\section{Construct Reliability and Validity}

In 1987, Hamersley's defined the term 'validity' as "an account is valid or true if it represents accurately those features of the phenomena, that it is intended to describe, explain or theorized" (Hamersley's, 1987, p-69). This definition is widely acknowledged and much quoted in the literature. Later, in 2003, Collis \& Hussey, defined validity as "extent to which the research findings accurately represent what is really happening in the situation" (Collis \& Hussey, 2003, p-357). Basically, validity encompasses the whole experimental concept and highly concerned whether the obtained results fulfill all the requirements of intended research. Conferring to the above, Bougie (2010), emphasized the importance of validity in research. Accordingly, validity is a testing/examining technique which identify the characteristics of instruments i.e how well it measures the concepts which is being understudied or which is intended to measure. In other words, validity is concerned with whether intended research we measure the right concept, as supported by researchers/authors like (Collis \& Hussey, 2003; Andy Field, 2009; Saunders, Lewis, \& Thornhill, 2009). So, in the current study, convergent validity and discriminant validity have been applied to validate the research work.

Table No 3: Construct Reliability and Validity.

\begin{tabular}{|l|c|c|c|}
\hline & $\begin{array}{c}\text { Cronbach's } \\
\text { Alpha }\end{array}$ & $\begin{array}{c}\text { Composite } \\
\text { Reliability }\end{array}$ & $\begin{array}{c}\text { Average Variance Extracted } \\
\text { (AVE) }\end{array}$ \\
\hline Culture & 0.889 & 0.908 & 0.526 \\
\hline Change Management & 0.770 & 0.847 & 0.584 \\
\hline $\begin{array}{l}\text { Transformational } \\
\text { Leadership }\end{array}$ & 0.811 & 0.834 & 0.506 \\
\hline
\end{tabular}

In the above Table No: 3 the minimum value of Cronbach's Alpha should be 70. It is used for the reliability of the research tool. The above table shows that the value of alpha is more than 70 , hence the tool used for the data collection is reliable.

\section{Discriminant Validity}
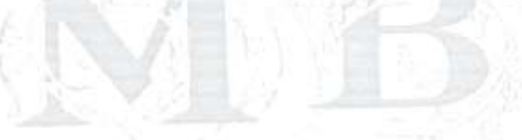

In this study for measurement of validity, the Discriminant validity approach has also been utilized. Discriminant validity basically applied to evaluates when different construct does not associate with each other construct. Accordingly, "discriminant validity is the degree to which measures of different concepts are distinct. The notion is that if two or more concepts are unique, then valid measures of each should not correlate too highly" (Bagozzi et al., 1991).Therefore, to support and validate the current research work, following three methods have been applied to measure and access the discriminant validity.

1. Fornell-Larcker Criterion.

2. Cross Loadings Analysis.

3. Heterotrait-Monotrait Ratio (HTMT).

\section{Fornell-Lacker's Criterion}

Fornell-Lacker's criterion is one of the most important discriminant validity measurement method. According to Fornell-Lacker's criteria the square root of average variance extracted (AVE) of each factor should be greater or larger than the correlation coefficients between the factor in question and other factors. According to the concept of Fornell-Lacker's criterion, the discriminant validity for the given research work is established. The detailed has been presented in tabulated form. The given Table No: 4 showed that the AVE values of each variable falls within the acceptable limit and there have been established positive discriminant validity among the variable. 
Table. No 4: Fornell-Larcker Criterion

\begin{tabular}{|l|c|c|c|}
\hline & Culture & Change Management & Transformational leadership \\
\hline Culture & 0.725 & & \\
\hline Change Management & 0.259 & 0.764 & \\
\hline Transformational leadership & -0.357 & -0.002 & 0.711 \\
\hline
\end{tabular}

The Fornell-Larcker criterion Table No: 4 suggest that each latent variable should have a higher $r$-square with itself. The diagonal statistics ( $\mathrm{r}$-square) given in the above table indicates that each latent variable is higher on itself. Note that, the diagonals are the square root of AVE of the latent variable and shows that there is discrepant validity.

\section{Cross Loadings}

Another important method which has been utilized in the present study to assess discriminant validity is through the cross loadings analysis. Cross loadings as its name implies can be determined if an item is belonging to a particular construct and loads strongly on another construct/measure in the study. For the current study, the cross loadings of all construct illustrated in Table No 5. The table exhibit the details of correlations among the item with the latent construct. According to McLure Wasko, \&Faraj (2005), factor loadings of all indicators should be greater than the constructs of them than any other factors in the loadings table to establish discriminant and convergent validity. The results indicate that all the factor loading for items in a particular construct are greater than their cross-loadings providing additional support for discriminant validity. According to Hulland (1999), discriminant validity is established when the diagonal loadings are significantly greater than the off-diagonal loadings in the corresponding rows and columns.

Table 5: Cross Loading

\begin{tabular}{|l|c|c|c|}
\hline & Culture & $\begin{array}{c}\text { Change } \\
\text { management }\end{array}$ & $\begin{array}{c}\text { Transformational } \\
\text { leadership }\end{array}$ \\
\hline C1 & $\mathbf{0 . 6 3 4}$ & 0.263 & -0.160 \\
\hline C2 & $\mathbf{0 . 6 6 4}$ & 0.050 & -0.290 \\
\hline C3 & $\mathbf{0 . 6 6 7}$ & 0.033 & -0.336 \\
\hline CI4 & $\mathbf{0 . 6 4 5}$ & -0.076 & -0.285 \\
\hline C5 & $\mathbf{0 . 6 9 3}$ & 0.108 & -0.148 \\
\hline C6 & $\mathbf{0 . 8 1 2}$ & 0.158 & -0.309 \\
\hline C7 & $\mathbf{0 . 8 0 9}$ & 0.199 & -0.272 \\
\hline C8 & $\mathbf{0 . 8 0 5}$ & 0.374 & -0.249 \\
\hline C9 & $\mathbf{0 . 7 6 6}$ & 0.332 & -0.272 \\
\hline CM4 & 0.097 & $\mathbf{0 . 6 2 9}$ & 0.121 \\
\hline CM5 & 0.215 & $\mathbf{0 . 7 8 6}$ & -0.005 \\
\hline CM6 & 0.271 & $\mathbf{0 . 8 7 4}$ & -0.069 \\
\hline CM7 & 0.132 & $\mathbf{0 . 7 4 7}$ & 0.052 \\
\hline TL1 & -0.310 & -0.068 & $\mathbf{0 . 8 0 6}$ \\
\hline TL2 & -0.003 & 0.012 & $\mathbf{0 . 6 5 0}$ \\
\hline TL3 & -0.112 & 0.027 & $\mathbf{0 . 6 6 2}$ \\
\hline TL4 & -0.061 & -0.047 & $\mathbf{0 . 5 8 6}$ \\
\hline TL5 & -0.343 & 0.057 & $\mathbf{0 . 8 2 3}$ \\
\hline
\end{tabular}


In Table No: 5 to assess the discriminant validity all the items should vertically and horizontally load on one latent variable. The above table indicates that these conditions are met and the item score is high vertically and horizontally on one latent variable. All the items tagged as OC are loaded on Organizational Culture. Similarly all the items tagged as CM on the factor called Change Management. The remaining factors tagged as TL are loaded on Transformational leadership.

\section{Heterotrait-Monotrait Ratio (HTMT):}

HTMT (heterotrait-monotrait) is an estimate of the correlation between the constructs. It is referred to as a new criterion for assessing discriminant validity in variance-based SEM (structural equation modelling).Interpretation of HTMT analysis is easier. For the measurement of discriminant validity, the HTMT estimate involved comparing mechanism with a prespecified.

Table No 6: Heterotrait-Monotrait Ratio (HTMT)

\begin{tabular}{|l|c|c|c|}
\hline & $\begin{array}{c}\text { Organizational } \\
\text { Culture }\end{array}$ & $\begin{array}{c}\text { Change } \\
\text { Management }\end{array}$ & $\begin{array}{c}\text { Transformational } \\
\text { leadership }\end{array}$ \\
\hline Organizational Culture & & & \\
\hline Change Management & $\mathbf{0 . 3 2 0}$ & & \\
\hline $\begin{array}{l}\text { Transformational } \\
\text { Leadership }\end{array}$ & $\mathbf{0 . 3 2 1}$ & $\mathbf{0 . 1 3 9}$ & \\
\hline
\end{tabular}

HTMT is used in Table No 6 to assess the discriminant validity in structural equation modeling. The most conservative threshold value of HTMT is 0.85 and to establish the discriminant validity the value of HTMT should be less than 0.85 . In the table given above it is evident that all three values are less than 0.85 , therefore it can be concluded that the discriminant validity is established. There is discriminant validity between OC and CM, OC and CM, CM and TL.

\section{Discussion}

Summarizing the above description it can be said that research study may be vital from the perspective of higher educational institute's employees. The study also has importance from the perspective of the organization that these HEIs' employees put their heart and soul for the betterment of the organization and they exhibit voluntary behaviors to make the organization successful

The results of the study showed that, the organizational culture had positive and significant effect on change management. Thus Hypothesis $\mathrm{H}_{1}$ was accepted. It showed that higher the citizenship behavior higher was the change management of sub contractual employees. So this voluntary behavior has influenced change management of sub contractual employee. This result was consistent with the findings of (Chien, 2007), he found that organizational culture had positive effect on commitment towards the organization. The Organizational culture was further supported by three measures (Involvement, Change and Organizational culture). Involvement was found to have positive and significant effect on change management. Thus, Hypothesis $\mathrm{H}_{2}$ was accepted. It represented that sub contractual employee exhibits helping behavior towards their employees. This result was consistent with the findings of (Yen \&Neihoff, 2004) found in their study that Involvement had positive effect on organizational performance and commitment.

Change had significant and positive effect on change management. Thus, Hypothesis $\mathrm{H}_{5}$ was accepted. The employees showed change behavior by being nice, kind, polite and respectful to coworkers around them. This result was consistent with the findings of (Elizbeth, 1996) as she found in her study that change behavior had positive relationship with change management. Further it showed that employees appreciated their colleagues and were well aware of the rights of their colleagues. Organizational culture also had 
significant and positive effect on change management. Thus, Hypothesis $\mathrm{H}_{6}$ was accepted. It showed that employees, by exhibiting organizational culture behavior they avoided negative behaviors towards their coworkers. This result was consistent with the findings of (Elizbeth, 1996) she found in her study that organizational culture behavior had positive relationship with change management. The study of (Podsakoff, Micheal\& Mackenzie, 1997) found that organizational culture had positive effect on commitment to the organization. In other words it can be said that the organizational culture behavior deals with the willingness to tolerate less than ideal circumstances without complaining and refraining from activities such as complaining and petty grievances.

\section{Conclusion}

The purpose of the study was to examine the effect of organizational culture on change management. The findings of the current study have supported that sub contractual employee's involvement despite the fact that these employees are not permanent employees. The study has further supported that behaviors like Involvement, change and organizational culture being facets of organizational culture have shown significant and positive effect on change management. The management of the organizations who have employed sub contractual employees should focus on Involvement (helping behavior), change (being nice. Polite and respect full behavior) and organizational culture (avoiding negative behavior), to promote adaptability that will take the change management of sub contractual employees to a further level.

\section{Limitations}

Although it has been tried to make the study comprehensive enough but still the study is with some limitations as discussed below.

- Conducting a country wide research was not feasible that is why the research was limited to Peshawar Region. The sample size is also a limitation it can be increased in suitable circumstances. It was a cross sectional study whereas a longitudinal study can give improved results. Because it was crosses sectional study that is why it was not possible to establish a causal relationship.

\section{References}

Burnes, B. (2004). Kurt Lewin and the planned approach to change: a re-appraisal. Journal of Management studies, 41(6), 977-1002.

Burnes, B., \& Cooke, B. (2012). The past, present and future of organization development: Taking the long view. Human Relations, 65(11), 1395-1429.

Cameron, E., \& Green, M. (2004). Making sense of change management. Great Britain: Kogan Page Limited.

Denison, D., Nieminen, L., \& Kotrba, L. (2014). Diagnosing organizational cultures: A conceptual and empirical review of culture effectiveness surveys. European Journal of Work and Organizational Psychology, 23(1), 145-161.

Franken, A., Edwards, C., \& Lambert, R. (2009). Executing strategic change: Understanding the critical management elements that lead to success. California Management Review, 51(3), 49-73.

Hatch, M. J., \& Zilber, T. (2012). Conversation at the border between organizational culture theory and institutional theory. Journal of Management Inquiry, 21(1), 94-97.

James, K. (2015). Leadership Special Interest Group: What is leadership? Canadian Oncology Nursing Journal/Revue canadienne de soins infirmiers en oncologie, 25(1), 114-115.

Priola, V., \& Hurrell, S. A. (2011). Organisational culture and change management. 